\title{
Não Excluam Metade da Humanidade da Geografia Humana: entrevista com Janice Monk
}

\section{On Not Excluding Half of the Human in Human Geography: interview with Janice Monk}

\author{
Joseli Maria Silva \\ Universidade Estadual de Ponta Grossa \\ joseli.genero@gmail.com
}

Em março de 2010 lançamos o primeiro número da Revista Latino-americana de Geografia e Gênero, justamente quando Janice Jones Monk, uma das mais importantes colaboradoras para o desenvolvimento da perspectiva de Gênero na ciência geográfica, completava setenta e três anos de vida. Janice Monk nasceu em 13 de março de 1937 em Sidney, Austrália, mas viveu a maior parte de sua vida nos Estados Unidos, onde se dedicou mais de cinquenta anos na produção do conhecimento geográfico, quase que integralmente baseado na vertente feminista. Janice Monk fez seu doutorado em Geografia na Universidade de Illinois, em 1972, momento de forte expansão do pensamento feminista naquele país. A experiência profissional desta geógrafa é extensa e sua contribuição para o desenvolvimento do pensamento geográfico, notadamente para os estudos de gênero, é inestimável. Atualmente Janice Monk é Pesquisadora Emérita em Ciências Sociais - estudos de mulheres, professora do departamento de Geografia e Desenvolvimento da Universidade do Arizona e Membro Sênior da Associação Americana de Geógrafos. Além de atuar intensamente no campo acadêmico, participa ativamente de instituições como Conselho Nacional de Educação Geográfica, Conselho Nacional de Pesquisas sobre a Mulher, Sociedade de
Mulheres Geógrafas, União Geográfica Internacional e também da Associação Americana de Geógrafos, da qual foi presidente entre 2001 e 2002.

Explorar a trajetória de vida desta ilustre geógrafa, cuja existência se confunde com a história do pensamento feminista na Geografia, é uma grande oportunidade para expressar uma versão feminina de nossa história científica, repleta de nomes masculinos. Mas além de apresentar outras versões diferentes do pensamento hegemônico, esta entrevista pretende ser uma inspiração para a construção de um pensamento geográfico feminista latino-americano.

A entrevista está estruturada em três eixos que estão inter-relacionados e refletem os traços da produção científica de Janice Monk. O primeiro está relacionado com a construção da visibilidade de grupos sociais minoritários na Geografia, como o das mulheres, a partir do pensamento feminista. $\mathrm{O}$ segundo eixo de diálogo baseia-se no processo de desenvolvimento da vertente feminista no pensamento geográfico e o terceiro, direciona a entrevista para as perspectivas de produção de uma Geografia Feminista baseada em alianças entre diferentes lugares do mundo. 
Joseli Maria Silva: O início da luta pela visibilidade feminina e a crítica ao carácter masculino da Geografia estão expressos no artigo "On Not Excluding Half of the Human in Human Geography” publicado com Susan Hanson em 1982 em The professional geographer. Qual foi o impacto dessas ideias no meio acadêmico, na época do lançamento?

Janice Monk: Quando Susan e eu escrevemos este artigo, nosso objetivo era contribuir náo somente ao emergente campo das Geografias das Mulheres, mas questionar a tendência central da disciplina, suas propostas, teorias e métodos de fazer pesquisa. Nós queríamos alcançar grandes audiências, náo apenas daquelas que estavam sendo pioneiras em abordar a vida das mulheres. Nos anos em que vimos o artigo denominado como 'indiscutivelmente' o mais recente e significante artigo, o qual desde então, ficou conhecido como 'Geografia Feminista' (JONES, NAST e ROBERTS, 1997, p. xxi), as reaçóes iniciais das Geógrafas Feministas, as quais publicaram comentários sobre o artigo, sugeriram que não entenderam nossa intenção. $\mathrm{O}$ artigo foi identificado como um modelo do tipo "adicione mulheres e mexa”, criticado por não ir longe o suficiente, ou por não assumir as diferenças entre as perspectivas feministas socialistas, radicais e liberais. De modo interessante, a interpretação do documento como representando uma 'etapa' a qual simplesmente defendeu a adição das mulheres, persistiu em alguns resumos feministas do desenvolvimento histórico deste campo. Nós ainda encontramos exemplos de geógrafos cujo foco não era essencialmente os estudos de gênero que entenderam nossa proposta e modificaram seus trabalhos, por exemplo, em estudos de migraçáo, para 'não excluir a metade do mundo'. Susan e eu exploramos as várias maneiras que o artigo foi recebido, analisando suas citaçóes nos anos seguintes (HANSON e MONK, 2008). Nesta reflexão notamos que a Geografia Anglofônica Feminista e o nosso próprio trabalho evoluiu, particularmente, com o aumento de atenção às questóes de subjetividade e identidade, nós ainda mantemos nossos objetivos de promover práticas não sexistas em nosso trabalho e em nossas vidas.

JMS: O seu texto 'Many Roads: The Personal and Professional Lives of Women Geographers' explora o curso da vida de mulheres geógrafas, vinculando a vida privada, pessoal e a profissional em espaços públicos. No início do artigo 'When in the World are Women' também há um resgate biográfico. Esta característica é específica do campo feminista? Quais as razóes da utilização de tal abordagem e a sua influência nos resultados de pesquisa?

JM: A introdução das relaçóes entre vida pessoal e profissional no capitulo 'Many Roads' foi conduzido parcialmente pelo trabalho que eu tenho feito desde o final dos anos 80 , sobre a forma como as faculdades e carreiras são moldadas por grandes culturas sociais e políticas, bem como por experiências pessoais. E estas, expressas por escrito, defenderam a atenção ao 'posicionamento' (tanto do pesquisador quanto daqueles sendo pesquisados) e 'reflexividade' da parte do pesquisador em considerar como seus pontos de vista são interaçôes modeladoras nesta área. Meu objetivo também tem sido mostrar que nosso trabalho geográfico tem que ser contextualizado em seus lugares e tempos. Na parte, a qual você se refere, 'When in the World are Women?', que primeiramente apareceu no livro Full Circles: Geographies of Women Over Life Course (1993), Cindi Katz e eu queríamos escrever uma introdução que ilustraria como lugar e tempo eram importantes nas vidas das mulheres e alertar os leitores sobre ideias ainda não exploradas na Geografia Feminista. Nós também pensamos que seria uma leitura interessante se 'histórias' autobiográficas fossem usadas. As minhas, focando o tempo, o mundo espacial de quatro geraçóes de mulheres na minha própria família, e as da Cindi, nos exemplos comparativos de lugar. Ela analisa como sua idade/fase $\mathrm{da}$ vida eram diferentes das garotas e mulheres no $\mathrm{Su}$ dão, onde ela conduziu pesquisa de campo. Ainda pensamos, naquela época, que muito da pesquisa feminista pressupunha que o campo estava relacionado à vida das mulheres em seus anos reprodutivos/meia-idade, e nós queríamos expandir esta visão. Desde aquela época, os trabalhos geográficos sobre crianças e juventude, uma raridade nos anos 90, se expandiram consideravelmente, tanto que agora há uma revista especializada, Children's Geographies. Pesquisas geográficas sobre idosos recebe menos atenção, apesar de estar começando a crescer, especialmente em partes do mundo como a Europa Ocidental, onde o envelhecimento demográfico está se tornando mais acentuado. Um recente manual analisando as perspectivas na Geografia Social inclui um capítulo sobre idade e envelhecimento que introduz as perspectivas do curso de vida (um conceito que trata das transiçóes, não simplesmente de etapas distintas) e se refere brevemente ao nosso livro Full Circles (PAIN e HOPKINS, 2010), mas isso, após um intervalo de quase duas décadas desde que o escrevemos.

JMS: O artigo 'Practically All the Geographers Were Women' evidencia a atuação das mulheres em vários espaços na Geografia, ao mesmo tempo em que torna visível as dificuldades encontradas por estas mulheres pioneiras. A crescente feminização do campo científico trouxe mudanças epistemológicas e metodológicas na produção do pensamento geográfico?

JM: Esta resposta pode ser 'não e sim'. No meu artigo 'Women, Gender, and the Histories of American Geography' (2004), eu pretendo mostrar como histórias sociais , políticas, e também as historias de ensino superior, tem historicamente colocado as mulheres em lugares diferentes dos homens dentro da disciplina. Do final do século XIX até a metade do século XX nos Estados Undos, por exemplo, grande parte da educação dos 
professores era realizada no que inicialmente era chamado 'escolas normais'. Eles ofereciam cursos de dois anos de duração. Mais tarde, estas instituiçôes ficaram conhecidas como 'Faculdades Estaduais de Professores' (com cursos de quatro anos), e posteriormente como Universidades Estaduais. Como ocorreram estas transiçôes, as funçôes destas instituiçóes que eram, preparar professores para escolas, mudaram para currículos mais amplos. Em seus primeiros anos, muitos dos geógrafos nas escolas normais eram mulheres, já que ensinar era identificado como uma profissáo para mulheres de classe media. Nesta época, a Geografia não era muito ensinada em universidades, mas como as universidades cresceram, elas favoreceram contratar ('brilhantes, jovens') homens, não mulheres (de meia-idade). Muitas das mulheres no início das Faculdades de Professores eram profissionalmente muito ativas, e tinham cargos de liderança no Conselho Nacional de Professores de Geografia (mais tarde Conselho Nacional de Educação Geográfica). Elas publicavam, especialmente no Journal of Geography (focando na educação) e escreviam livros. Algumas viajavam muito, nacional e internacionalmente e faziam pesquisas de campo. Algumas de suas publicaçóes revelam a atenção para as meninas e meninos e questóes de diversidade (por exemplo, etnicidade, ou consciência de crianças imigrantes). Mas, elas também trabalhavam dentro de paradigmas maiores de sua época, nos quais náo estavam distintamente presentes as visóes feministas. Durante a Segunda Guerra Mundial, outra mudança profissional, porém temporária, ocorreu quando muitas mulheres foram recrutadas pelas agências do Governo Federal para tarefas de mapeamento. Reciprocamente, nas décadas de 50 e 60, foram os pontos mais baixos na representação e visibilidade da mulher na Geografia, marcada como uma sociedade americana pós-guerra e por uma cultura conservadora de casa e família. As gerações anteriores de mulheres Geógrafas estavam se aposentando, as universidades ainda estavam crescendo; os homens eram os que já estavam contratados, a proporçáo das mulheres entre os geógrafos diminuiu, e o pensamento cientifico deste período focou-se no novo positivismo e nas perspectivas quantitativas, nas quais estes poucos geógrafos eram socializados. Então, os movimentos feministas que floresceram na sociedade no início dos anos 70 viram uma nova geração de mulheres buscando vidas profissionais, e elas foram influenciadas pela nova consciência, que trouxeram para seu trabalho quando buscavam (e frequentemente lutavam) por posiçóes em universidades. Era este grupo de mulheres que nutria as perspectivas femininas na pesquisa e ensino. $\mathrm{O}$ mesmo período viu o desenvolvimento de estudos feministas entre disciplinas e a introdução de programas de estudo de mulheres (mais tarde estudos de gênero) nas universidades americanas, de modo que as mulheres na Geografia tiveram uma comunidade acadêmica de referência mais ampla. Havia correntes políticas adicionais, mas isto está além do alcance desta entrevista. Mas, meu argumento prin- cipal é que as tendências do pensamento não são independentes de paradigmas predominantes, estruturas de poder e forças sociais mais amplas.

JMS: Depois de tantas décadas de avanço da perspectiva feminista na Geografia, quais são, em sua opinião, as principais contribuiçóes desta perspectiva para a ciência geográfica como um todo?

JM: A meu ver, as maiores contribuiçóes têm sido prestar mais atenção aos múltiplos aspectos da diversidade, não somente ao gênero, mas também a raça, a etnicidade, a sexualidade e a juventude. Adicionalmente, estudos feministas tem sido o ponto central em promover a atenção a métodos qualitativos, e as questôes filosóficas e metodológicas, tais como aspectos da subjetividade, 'reflexividade', 'posicionalidade', as interseçôes das identidades, e aspectos da vida, tais como as emoçóes que estáo entrelaçadas com as experiências e formas de espaços e lugares. Estas ideias agora permeiam as múltiplas áreas da Geografia Humana (cultural e social), não apenas no trabalho no qual, o gênero é central.

JMS: As Geografias Feministas se desenvolveram em variados caminhos teórico-metodológicos que, de certa forma, ainda convivem. $\mathrm{Na}$ atualidade, quais são as contribuiçôes do pós-estruturalismo, pós-colonialidade e da perspectiva queer para o campo das Geografias Feministas?

JM: A minha resposta a esta pergunta repetiria muito do que eu escrevi na pergunta anterior: maiores preocupações com as complexidades de diferença, diversidade, subjetividade e corpo, e também pensar conhecimento como construçáo social, cultural e política, entrelaçados com relaçóes de poder.

JMS: Sua trajetória de pesquisa, expressa em vários artigos científicos, evidencia uma preocupação com a perspectiva do 'outro' e parcerias estabelecidas com pesquisadoras fora do âmbito acadêmico anglo-saxão. Esta prática, contudo, não é uma característica geral da geografia feminista, ainda fortemente fechada dentro dos países de língua inglesa. Porque esta vertente que trabalha contestando autoridades discursivas, contraditoriamente, ainda não expandiu alianças entre pesquisadores oriundos de países de contextos culturais e econômicos desfavoráveis?

JM: Em parte é por causa do domínio da Língua Inglesa e a falta de multilinguismo entre os falantes nativos do Inglês. Em parte são as pressóes políticas neoliberais para que os professores universitários anglófonos publiquem com frequência e rapidez e centrem-se em teorias em detrimento do processo moroso de aprender outras línguas e fazer um trabalho empiricamente sustentado. Em parte é a mudança nas práticas de publicação, com a relativa expansão das editoras comerciais no mundo 
anglófono, tomando as revistas acadêmicas que costumavam ser publicadas pelas sociedades científicas e por universidades, e a cultura de classificar o prestígio destas revistas. Tais políticas acadêmicas desencorajam os estudiosos anglófonos de publicar em outras línguas (mesmo que eles sejam competentes nestas línguas) ou ir além dos seus sistemas nacionais (ou britânico / americano) de publicar em revistas normalmente fora do sistema de classificação. Há algumas ironias nesta situação - Geógrafos anglófonos Humanos, têm buscado grande parte de suas orientaçóes teóricas na Europa Continental (por exemplo, dos filósofos franceses), assim como geógrafos de algumas tradiçóes fora do meio anglofônico podem aderir aos estudos mais positivistas, empíricos e aplicados. Além de apreciar e estar envolvida com geógrafos além do meu ambiente local, eu lamento estas outras tendências, mas também reflito a razão de eu ter escolhido meu caminho. Em certa medida, eu atribuo esta escolha por ter crescido na Austrália, fora da 'área' britânico americana, em uma família de baixa renda, em um lugar e tempo onde os imigrantes não britânicos estavam chegando em números substanciais e nós tomamos consciência do 'outro'. Também era o tempo e lugar de estar em um sistema educacional que estava disponibilizando recursos à juventude, a qual, sem esses recursos náo teria tais oportunidades. Adicionalmente, jovens australianos, especialmente mulheres, vendo a si mesmas nas periferias e ainda náo estando prontas para se acomodar e serem esposas e máes, estavam sintonizadas em viagens internacionais, em ir para o 'exterior', mesmo que temporariamente. Em comparação, os jovens homens eram mais propensos a permanecer em casa devido suas carreiras. Como meu pai também tinha interesses em outas partes do mundo, mas não tinha recursos para viajar para o exterior, eu cresci com a consciência do não- local. Então, voltamos às interseçóes de gênero, classe, o que a educação oferece e retribui, lugar e tempo.

JMS: Que relaçóes podem ser estabelecidas entre o incremento teórico das Geografias Feministas e as práticas sociais? Qual o papel da pesquisa acadêmica na transformação social?

JM: Este é um assunto que eu pondero com alguma preocupaçáo. Eu acho que nós precisamos de teorias, mas também precisamos ver que diferença elas podem fazer na sociedade, colaborar e comunicar além do campo acadêmico e nacional. Estou satisfeita em ver o crescente interesse e compromisso de pesquisa de açáo participativa, uma abordagem na qual as Geógrafas Feministas têm mostrado um significante papel em manter a Geografia Anglófona. Nos 25 anos em que estive empregada no Southwest Institute for Research on Women na University of Arizona, estivemos sempre envolvidos em projetos que não somente produziam livros e artigos, mas também trabalhamos com professores, estudantes e grupos comunitários em projetos educacionais, em áreas tais como: saúde, economia, literatura, artes e em ensino de ciências para garotas. Nós colaboramos com colegas no norte do México, refletindo sobre nossa localizaçáo, perto da fronteira internacional, e vimos a distinta herança da nossa regiáo (nativo americana, mexicana americana e anglo americana) como ponto central de nossos projetos. Eu acredito que tais colaboraçôes e perspectivas multifacetadas são importantes para pesquisa acadêmica, ensino e trabalho comunitário.

JMS: O artigo 'Place Matters: Comparative International Perspectives on Feminist Geography' analisa as variaçôes espaciais do desenvolvimento das Geografias Feministas em diferentes países, considerando os diversos contextos culturais que influenciam a disciplina. Como podem ser incrementadas açóes de cooperação entre diferentes países para promover e disseminar livremente o conhecimento em uma realidade social em que o saber é cada vez mais privatizado e transformado em mercadoria?

JM: Como Geógrafos que acreditam que o lugar importa, talvez seja inevitável que onde nós estamos molde nossas maneiras de ver o mundo. Mas, nós estamos cada vez mais conscientes, como Geógrafos, da implicação da globalização na economia, em novos caminhos (não apenas os legados do colonialismo), através da tecnologia, migração, negócios e assim por diante e dos desafios ambientas globais. Assim, eu vejo como algo muito importante que Geógrafos, incluindo as Geógrafas Feministas, trabalhem para promover o entendimento que cruza a fronteira nacional, cultural e linguística. Isto leva tempo, comprometimento e recursos que podem se opor às recompensas oferecidas por nossos sistemas locais, mas, eu vejo isto como gratificante, bem como essencial.

\section{Referências}

JONES III, John Paul, NAST, Heidi J., ROBERTS, Susan M.. Thresholds in Feminist Geography: difference, methodology, representation. Lanhan, Md. And Oxford: Rowman \& Littlefield Publishers, 1997.

MONK, Janice, HANSON, Susan.”On Not Excluding Half of the Human in Human Geography" . The Professional Geographer, v. 34, n 1, p. 11-23, 1982.

MONK, Janice, KATZ, Cindi. "When in the World are Women?”. In: KATZ, Cindi, MONK, Janice. Full Circles: Geographies of Women Over Life Course. London: Routledge, 1993. p. 1-26.

MONK, Janice. "Place Matters: Comparative International Perspectives on Feminist Geography”. The Professional Geographer, v. 46, n. 3, p. 277-288, 1994.

MONK, Janice. "Many Roads: The Personal and Professional Lives of Women Geographers." In: MOSS, Pamela. Placing Autobiography in Geography. Syracuse: Syracuse University Press, 2001. p. 167-187.

MONK, Janice. Women, Gender, and the Histories of Ame- 
Não Excluam Metade da Humanidade da Geografia Humana: entrevista com Janice

Monk

rican Geography. Annals of the Association of American Geographers, v. 94, n. 1, p. 1-22, 2004,.

MONK, Janice, HANSON, Susan. "On Not Excluding Half of the Human in Human Geography" . In: OAKES, Timothy, PRICE, Patricia L. The Cultural Geography Reader. New York: Routledge, 2008.

p. 365-372.

MONK, Janice, KATZ, Cindi. "When in the World are Women?”. In: BAUDER, Harald, ENGEL DI-MAURO, Salvatore. Critical Geographies: A Collection of Readings. Kelowna-Canadá: Praxis-epress, 2008. Disponível em: $<$ http://www.praxis-epress.org/CGR/17-Monk_and_Katz. pdf . Acesso em 30/03/2010. p. 218-40.

MONK, Janice. Practically All the Geographers Were Women. Presentation at Society of Woman Geographers Triennial, 2008. Disponível em: <http://www.iswg.org/ about1.html>. Acesso em 01/04/2010. 